\title{
Cesión de créditos contenidos en una factura y la notificación personal al deudor como requisito excluyente para su oponibilidad: Un fallo inquietante (Corte Suprema)
}

\author{
Comentario de Arturo Selman Nabum
}

Santiago, diez de mayo de dos mil once.

\section{VISTOS:}

En estos autos rol $N^{\circ} 19.407-2008$, del $7^{\circ}$ Juzgado Civil de Santiago, juicio en procedimiento ejecutivo por cobro de facturas "Comercial de Valores S.A. con Reutter Limitada" comparece don Luis Edgardo Hermosilla, abogado, en representación de Comercial de Valores S.A., solicitando que se despache en contra de Reutter Limitada, mandamiento de ejecución y embargo hasta por la suma de $\$ 303.527 .741$, más intereses, reajustes y costas, con el objeto de hacer íntegro y cumplido pago de lo adeudado a su representada.

Funda su acción en que se inició este procedimiento notificando judicialmente a la ejecutada las facturas No 01907 y 01951 , cedidas por Austral Food S.A., en las cuales constan créditos por las sumas de $\$ 107.856840$ y $\$ 195.669 .201$, respectivamente, y en el proceso se certificó que el demandado no consignó fondos, que no alegó la falsificación o la falta de entrega de mercadería o prestación de servicios y que el plazo para ello se encuentra vencido, por lo que las facturas sindicadas han adquirido plena fuerza ejecutiva, siendo su representada titular y legítima detentadora de aquellos títulos ejecutivos perfectos en los cuales constan obligaciones indubitadas, líquidas, actualmente exigibles y no prescritas, correspondiendo en consecuencia se dé lugar a la ejecución solicitada en los términos indicados.

La parte demandada opuso a la ejecución la excepción de pago parcial de la deuda consagrada en el artículo $464 \mathrm{~N}^{\circ} 9$ del Código de Procedimiento Civil, fundada en que la contraria ha demandado ejecutivamente el cobro de las facturas $\mathrm{N}^{\circ} 1907 \mathrm{y} \mathrm{N}^{\circ} 1951$, por la suma de $\$ 90.636 .000$ y $\$ 164.427 .900$, ambas más IVA, emitidas los días 2 y 18 de enero respectivamente, pues había hecho pagos parciales a las mismas antes de la fecha en que fuera notificada la cesión de aquellas referidas facturas.

Agrega que respecto de la factura 1951 con fecha 18 de enero de 2008, su representada pagó a Austral Food S.A., cedente de la factura, el valor neto, esto es, la suma de $\$ 164.427 .900$ mediante cheque $\mathrm{N}^{\circ} 5040601$ del Banco Estado en cuyo reverso consta no solo el número de factura que se pagó, sino también los datos que Austral Food S.A. agregó respecto de su cuenta corriente, para efectos de su depósito en ella, por lo que 
el saldo adeudado es $\$ 31.241 .301$ que corresponde al IVA y no los $\$ 195.669 .201$ pretendidos por la ejecutante.

En cuanto a la factura 1907 señala que con fecha 4 de enero de 2008, esto es, dos días después de su emisión, su representada realizó una transferencia electrónica de fondos desde su cuenta en el Banco Estado a la cuenta de Austral Food S.A., por la suma de $\$ 362.942 .400$, lo que corresponde al valor neto de tres operaciones entre Austral Food S.A. y su representada, las que se individualizan en el respectivo documento como CC8-001, CC8-002 y CC8-003 que corresponden a las facturas 1905, 1906 y 1907, por la suma de $\$ 181.670 .400$ más IVA, la primera de ellas y por la suma de $\$ 90.636 .000$ más IVA, cada una de las dos restantes. Agrega que de la sola lectura de la factura 1907 se desprende claramente que ella corresponde a la operación CC8-003, por lo que el valor neto de $\$ 90.636 .000$ se encuentra pagado.

Evacuando el traslado la parte ejecutante solicita el rechazo de la excepción, con costas. Se funda en que respecto de la factura 1951, la controversia debe circunscribirse a los \$164.427.900 que la contraria dice haber pagado, lo cual no ha acontecido. Agrega que la deuda emanada de la factura es $\$ 195.669 .201$ y no $\$ 164.669 .201$, por lo que cualquier antecedentes por una cifra distinta a la de la obligación de autos, no tiene por qué ser vinculado a su pago efectivo. El relato de la ejecutada carece de plausibilidad, pues el cheque en que se funda se refiere a otra operación anterior entre las mismas partes.

En relación a la factura 1907 por la suma de $\$ 107.856 .940$, el monto de la transferencia de fondos a que hace referencia la ejecutada $\$ 362.942 .400$, en nada se condice con el valor de la factura 1907, cuyo cobro se procura en estos autos, por lo que no existe antecedente alguno en el proceso que permita vincular la transferencia invocada por la contraria con el crédito adeudado en autos.

La sentencia de primera instancia, de veintiséis de marzo de dos mil nueve, corriente a fojas 102 y siguientes, rechazó las excepciones opuestas al remate.

Apelado el fallo por la ejecutada, una de las Salas de la Corte de Apelaciones de Santiago, por sentencia de seis de octubre de dos mil nueve, que se lee a fojas 234 , revocó el fallo en cuanto rechazó la excepción de pago opuesta por la ejecutada; y declaró, en su lugar, que tal excepción queda acogida parcialmente, por los montos indicados, debiendo seguirse adelante la ejecución hasta el entero y cumplido pago de lo efectivamente adeudado en capital, intereses y costas.

En contra de esta última decisión la parte ejecutante dedujo recursos de casación en la forma y en el fondo, siendo declarado inadmisible el primero de ellos mediante resolución de fecha dieciocho de marzo de dos mil diez, que se lee a fojas 278 .

Se ordenó traer los autos en relación respecto del recurso de casación en el fondo.

\section{CONSIDERANDO:}

Primero: Que el recurrente sostiene que la sentencia de segundo grado que revocó el fallo de primera instancia, acogiendo parcialmente la excepción de pago, en los términos expresados en la parte expositiva, ha sido dictada con infracción a los artículos 163 del Código de Comercio, en relación al artículo $10^{\circ}$ de la Ley $\mathrm{N}^{\circ} 19.983$; y artículo 1576 inciso primero del Código Civil, según pasa a explicar: 
Argumenta realizando una contextualización de la Ley $\mathrm{N}^{\circ} 19.983$, refiriéndose específicamente al artículo $5^{\circ}$ de la referida Ley, señalando que este establece una serie de requisitos copulativos, que cumplidos tendrían dos consecuencias, esto es que la factura podría ser cedible y que esta tendrá mérito ejecutivo para su cobro, todo ello para otorgar seguridad a quienes se hacen de las facturas.

Al respecto señala que quedó como un hecho asentado en el proceso, según se desprende del considerando sexto de la sentencia -el que no fuera revocado en esta parte por el tribunal de alzada-, que existe un claro recibo estampado en las facturas, de este modo, se ha vulnerado flagrantemente el precepto legal referido, toda vez que en un considerando tiene por acreditado el cumplimiento de los requisitos del artículo 5 de la Ley $\mathrm{N}^{\circ} 19.983$, no obstante lo cual, se niega a otorgarle a las cuartas copias de facturas, el efecto jurídico que la ley establece.

Añade que la sentencia impugnada infringe el artículo 163 del Código de Comercio en relación a lo dispuesto en el artículo 10 de la Ley $\mathrm{N}^{\circ} 19.983$, por cuanto la cesión de que se desprende la presente ejecución da cuenta de una operación eminentemente mercantil, por lo que la naturaleza de la cesión ha fijado el régimen jurídico que regirá a los intervinientes, siendo aplicable el Título IV del Libro II del Código de Comercio.

Agrega, conforme a lo anterior, que el título cedido y destinado a circular es la cuarta copia de la factura, las que en el caso de autos no contienen mención a pago parcial alguno, por lo que la excepción opuesta es a su juicio una alegación extradocumental, y que al momento de ser notificada la cesión de los créditos a Reutter, esta no alegó la excepción de pago parcial que invoca dentro del plazo de tercero día.

Sostiene que se contraviene, también, el artículo 1576 inciso primero del Código Civil, basado en que el presunto pago efectuado con fechas 13 y 14 de febrero de 2008 a Austral Food S.A. es inoponible a su representada y cesionaria de la factura $\mathrm{N}^{\circ} 1907$, puesto que dicho pago se habría realizado a la cedente del crédito quien a esa época ya no detentaba la calidad de acreedora de la obligación que hipotéticamente se habría solucionado parcialmente.

Pide finalmente que se anule la sentencia recurrida y se dicte sentencia de reemplazo que subsane los vicios denunciados, declarando que debe proseguirse con la ejecución en contra de la demandada, hasta el íntegro y cumplido pago de la totalidad de los créditos derivados de las facturas cobradas en estos autos.

SEGUNDO: Que para una adecuada inteligencia del asunto y resolución del recurso de casación en el fondo interpuesto, cabe tener presente las siguientes circunstancias del proceso, que se dieron por establecidas por los jueces de la instancia:

1.- Que con fecha 2 de enero de 2008 se emitió por Austral Food a Reutter Limitada la factura $\mathrm{N}^{\circ} 1907$ por un monto total neto de $\$ 90.636 .000$, más un IVA de $\$ 17.220 .840$, lo que hace un total de efectivo de $\$ 107.856 .840$.

2.- Que con fecha 18 de enero de 2008 se emitió por Austral Food a Reutter la factura $\mathrm{N}^{\circ} 1951$ por un monto total neto de $\$ 164.427 .900$, más un IVA de $\$ 31.241 .301$, lo que hace un total de efectivo de $\$ 195.669 .201$.

3.- Que el día 2 de enero de 2008 la ejecutada giró cheque a nombre de Austral Food S.A. por la cantidad de $\$ 90.636 .000$, que corresponde al valor neto de la factura 
$\mathrm{N}^{\mathrm{0}} 1907$, documento que no fue pagado por el Banco y devuelto "protestado por endoso irregular".

4.- Que con fecha 4 de enero de 2008, el Gerente de Administración y Finanzas de Austral Food S.A., envió a Reutter Limitada tres cheques devueltos protestados por endoso irregular, entre ellos, el cheque $\mathrm{N}^{\circ} 5040598$, y solicitó se hiciese una transferencia por \$362.942.400 a la cuenta $\mathrm{N}^{\circ} 18321160$ del Banco de Crédito e Inversiones a nombre de Austral Food S.A.

5.- Que con fecha 0 de enero de 2008 se realizó transferencia de fondos, a través del Banco del Estado, desde la cuenta corriente 000-0-043788-3 de Reutter S.A. a la cuenta corriente $\mathrm{N}^{\circ} 18321160$ del Banco de Crédito de Inversiones a nombre de Austral Food S.A., por la cantidad de $\$ 362.942 .400$, referencia "CC8-001; CC8-002 y CC8-003.

6.- Que con fecha 4 de enero de 2008 figura como movimiento en cartola de la cuenta corriente 000-0-043788-3 del Banco del Estado a nombre del demandado, una anotación de débito el día 4 de enero de 2008 con glosa "transferencias por mandante clientes” por \$362.942.400.

7.- Que con fecha 13 de febrero de 2008 Reutter Limitada deposita en la cuenta corriente $\mathrm{N}^{\circ} 18321160$ del Banco de Crédito e Inversiones, a nombre de Austral Food S.A., las cantidades de $\$ 50.000 .000$ y $\$ 13.700 .000$, respectivamente.

8.- Que con fecha 21 de enero de 2008 se notificó a Reutter Limitada la cesión de las facturas $\mathrm{N}^{\circ} 1907$ y 1951 a Comercial de Valores S.A.

Tercero: Que la sentencia recurrida que, en lo pertinente a la excepción de pago formulada por la ejecutada, revocó el fallo de primer grado, acogiendo parcialmente la aludida defensa, únicamente por los montos de \$90.636.000, que corresponde al monto neto de la factura $\mathrm{N}^{\circ} 1907$, como asimismo el monto neto de la Factura $\mathrm{N}^{\circ} 1951$ por la cantidad de $\$ 164.427 .900$.

Arriban a la conclusión anterior los Jueces del fondo, basados en que de acuerdo al mérito probatorio de la documental no objetada, de la testimonial de ambos testigos, contestes en los hechos y no tachados y que dieron razón de sus dichos, se ha construido plena prueba, sin ser desvirtuada por otra en contrario, para dar por establecidos los elementos que conforman la excepción opuesta por la ejecutada, encontrándose probado el pago por las cantidades indicadas en el párrafo precedente.

Agregan que de los mismos antecedentes es posible inferir que el demandado no ha pagado el Impuesto al Valor Agregado correspondientes a ambas facturas por las cantidades de $\$ 5.259 .056$ y $\$ 31.241 .301$, respectivamente, hecho fue reconocido por el ejecutado.

Cuarto: Que en un primer capítulo, se invoca la infracción del artículo 163 del Código de Comercio en relación con el artículo 10 de la Ley $\mathrm{N}^{\circ} 19.983$, haciéndose hincapié en lo que señalan sus artículos $4^{\circ}$ y $5^{\circ}$, sosteniendo que allí se encuentra constituido un catálogo de requisitos copulativos y claros, los que cumplidos tendrían dos consecuencias: a) que las facturas podrían circular en el mercado económico, mediante la cesión de ellos y, b) que dichas facturas tendría mérito ejecutivo para su cobro y que esta última condición fue declarada en la gestión preparatoria de la vía ejecutiva. 
Para afirmar su convicción en relación a la denuncia del quebrantamiento del artículo 163 ya citado, expresa que la operación de cobro de facturas es netamente de carácter comercial y por ello resulta plenamente aplicable la disposición legal referida, entendiendo que, una vez notificada la cesión, el deudor que tenga que oponer excepciones que no resulte del título de crédito, deberá hacerlas presente en el acto de notificación, o dentro de tercero día a más tardar, so pena de que más adelante no serán admitidas. Por ello, concluye que como en las facturas no se menciona ningún pago parcial ni alteración del total en ellas indicado, la excepción de pago que opuso la ejecutada es una alegación extradocumental, afirmando que ello es concordante con lo estatuido con la norma legal que dice infringida, al disponer que posteriormente las excepciones dichas no serán admitidas, imponiendo una prohibición que no fue acatada por los jueces del fondo.

QuiNTo: Que, además, agrega el recurrente, que el fallo de segundo grado en sus fundamentos tercero y cuarto estudia la materia referida a la notificación en la etapa preparatoria haciendo presente que la demandada no opuso excepciones y por ello a las facturas individualizadas como la $\mathrm{N}^{\circ} 1907$ y No 1951, se les confirió mérito ejecutivo $\mathrm{y}$, sin embargo, en su motivo quinto agrega que ello no excluye que el demandado pueda oponer las excepciones del artículo 464 del Código de Procedimiento Civil, en la etapa propiamente del juicio ejecutivo, pues al notificársele la demanda, nace para el ejecutado el derecho de oponerse en virtud de las reglas generales del juicio ejecutivo;

Sexto: Que cabe observar que el recurrente no hace reproche alguno a la aplicación de los artículos 464 y 466 del Código de Procedimiento Civil en cuanto el tribunal de primera instancia declaró la admisibilidad de la excepción de pago parcial opuesto por el ejecutado, de manera que en esta etapa del procedimiento no resulta procedente que este tribunal de casación se pronuncie acerca de tal reproche y en consecuencia, debe tenerse también como un hecho de la causa que no ha sido controvertido;

SÉPtimo: Que en un segundo capítulo de casación de fondo, se acusa a los sentenciadores haber omitido la aplicación del artículo 163 del Código de Comercio, entendiendo que por tratarse de una operación mercantil, conforme a lo previsto en el artículo 10 de la Ley $\mathrm{N}^{\mathrm{o}} 19.983$ debió aplicarse aquella disposición y no acoger la excepción opuesta dado que el deudor, ahora ejecutado, debió hacerla presente en el acto de notificación de la cesión de aquellos documentos o, a más tardar, dentro de tercero día, lo que no aconteció. Así, estas excepciones que no resultan del crédito cedido no debieron ser admitidas. Agrega que en las facturas $\mathrm{N}^{\circ} 1907$ y N 11951 que motivan la ejecución no se menciona pago parcial ni alteración del total que señalan, lo que es suficiente para declarar la inoponibilidad de la excepción extradocumental;

Octavo: Que esta Corte Suprema, respecto de los requisitos que deben cumplirse en resguardo de los derechos del deudor, en materia de cesión de créditos, ha señalado en la causa Rol No 2563-2008, en sentencia de uno de septiembre de dos mil nueve que el derecho común ha sido muy riguroso al efecto y citando la memoria de prueba del 
profesor Alejandro Silva Bascuñán, titulada "La Cesión de Derechos" se refiere a esta materia en los siguientes términos: El artículo 1903 del Código Civil prescribe como requisito de este trámite (notificación de la cesión al deudor), que se haga con "exhibición del título que llevará anotado el traspaso del derecho con la designación del cesionario y bajo la firma del cedente" y prosigue: El espíritu de la ley es que el deudor se imponga personalmente de la existencia en poder del cesionario del documento justificativo del derecho transferido, en el cual aparece con la firma de su acreedor la designación del sustituto que por su voluntad le ha reemplazado. De este modo está en condiciones de imponerse de la veracidad de la transferencia" (pág. 1548).

Continúa la Corte señalando que "resulta evidente que si bien el espíritu de la Ley $\mathrm{N}^{\circ} 19.983$ privilegia la agilidad del tráfico de créditos mercantiles, para cuyo efecto facilita los trámites para la notificación de la cesión por parte del cesionario al obligado al pago de la factura, permitiendo llevarla a cabo mediante el despacho por un Notario Público de una carta certificada, adjuntando copias del respectivo título, certificados por el ministro de fe, lo que contrasta con el derecho común, en que la exigencia de exhibir el título al deudor que contempla el artículo 1903 del Código Civil, al momento de notificarle la cesión, ha llevado a la doctrina y a la jurisprudencia a afirmar que para el trámite en cuestión no se puede emplear la notificación subsidiaria del artículo 44 del Código de Procedimiento Civil, es menester concluir que los requisitos establecidos en el inciso segundo del artículo 7 de la Ley $\mathrm{N}^{\circ} 19.983$ para la notificación de la cesión al deudor, deben cumplirse en forma estricta, en atención a la delicada materia que reglamenta, máxime que con ella se pueda estar dando paso a la ejecución forzada de los créditos contenidos en las facturas" y agrega, "resulta evidente que la única forma en que, conforme lo comprendía el legislador procesal de la época, podía entenderse que se lograba acreditar el conocimiento de la cesión por parte del deudor, era mediante su notificación personal" y concluía así: "Si bien la exigencia en orden a que la notificación de la cesión del crédito deba ser personal no está expresamente contemplada en el Código de Comercio ni en el Código Civil, es aplicable a la materia de que se trata, por cuanto el artículo 47 del Código de Procedimiento Civil dispone que esta forma de notificación se empleará 'siempre que la ley disponga que se notifique a una persona para la validez de ciertos actos'” (Sentencias Rol N 3895-2000 de 27 de agosto de 2001, Rol No 2342-2003 de 23 de diciembre de 2004 y otros que cita).

Noveno: Que en este contexto, es dable concluir que las exigencias antes referidas no fueron cumplidas por el actor y, por ello, no es suficientemente válida la que se practicó efectuada a través de una carta certificada emitida por un Notario Público, apartándose de la correcta aplicación de las normas pertinentes referidas a las formalidades de la notificación;

DÉcımo: Que aún más del estudio de los antecedentes cabe advertir que los pagos referidos a los montos netos de cada una de las facturas $\mathrm{N}^{\circ} 1907$ y $\mathrm{N}^{\circ} 1951$ se efectuaron el 4 y 18 de enero respectivamente y es un hecho reconocido por la demandante que la deudora cedida fue notificada de la cesión mediante carta certificada enviada por el 
titular de la $45^{\circ}$ Notaria de Santiago, el 23 de enero de 2008, esto es, con posterioridad a los pagos parciales opuestos por el ejecutado y reconocidos en estos autos;

UNDÉcimo: Que desde otra perspectiva, cabe hacer presente que la excepción de pago es precisamente una excepción que afecta al título cedido, puesto que se trata de una excepción real y que puede ser opuesta tanto al acreedor del crédito como también al cesionario; según lo dice el inciso final del artículo 2354 del Código Civil, al estatuir que tales son aquellas son inherentes al a obligación principal, en el caso de autos, a la obligación de pagar;

Duodécimo: Que se denuncia, por último, la no aplicación de lo prescrito en el inciso $1^{\circ}$ del artículo 1576 del Código Civil, aduciendo que el deudor ha reconocido que con posterioridad a la notificación de la cesión de los créditos, depositó con fecha 13 y 14 de febrero de 2008 en la cuenta corriente del acreedor cedente las cantidades de $\$ 50.000 .000$ y $\$ 13.700 .000$ con el objeto de pagar parcialmente el IVA de sus facturas, una de las cuales es la $\mathrm{N}^{\circ} 1907$, por lo que según expresa sólo adeudaba de ésta el monto de $\$ 5.259 .056$ correspondiente al impuesto de valor agregado.

Entiende el recurso, que en todo caso debió señalarse y determinarse que lo adeudado de esa factura es el monto total del impuesto al valor agregado, es decir $\$ 17.220 .840$ pues es evidente que aquellos depósitos en la cuenta corriente del cedente fueron posteriores a la notificación de la cesión de crédito;

Decimotercero: Que al respecto caben a lo menos dos reflexiones: a) la primera atinente a la forma en que se practicó la notificación de la cesión de los créditos, dado que de acuerdo con lo expresado en los motivos que anteceden dicha notificación, no cumplió con los requisitos necesarios para obligar al deudor en relación al cesionario; b) en cuanto hecho de la causa resulta inamovible para este tribunal dado que no se ha denunciado violación a las leyes reguladoras de la prueba, de tal modo que los hechos asentados por los jueces del fondo no pueden ser revisados mediante el recurso en examen y; c) que en todo caso, se trataría de una proposición subsidiaria que por su naturaleza, no tiene cabida en un recurso de casación en el fondo;

Decimocuarto: Que, conforme a lo reflexionado, puede concluirse que las infracciones legales denunciadas no se han producido, de manera que el recurso debe ser desestimado.

Y visto, además, lo dispuesto en los artículos 163 del Código de Comercio, 1901, 1902, 1903, 1905 del Código Civil; 47, 464, 466, 764, 765 y 783 del Código de Procedimiento Civil y artículos 5, 7 y 10 de la Ley $\mathrm{N}^{\circ} 19.983$, se rechaza el recurso de casación en el fondo interpuesto a fojas 257 por el abogado don Leonel Stone Cereceda, en representación de Comercial de Valores S.A. Factoring, en contra de la sentencia de la Corte de Apelaciones de Santiago, de fecha seis de octubre de dos mil nueve, escrita de fojas 234 a fojas 249 , ambas inclusive. 
Regístrese y devuélvase.

Redacción del Abogado Integrante Sr. Jorge Medina Cuevas.

Rol No 26-2010.

Pronunciado por la Primera Sala de la Corte Suprema, por los Ministros Sr. Adalis Oyarzún M., Sra. Margarita Herreros M., Sr. Guillermo Silva G. y Abogados Integrantes Sr. Nelson Pozo S. y Jorge Medina C.

\section{Comentario}

El presente comentario abordará el pronunciamiento efectuado por la Corte Suprema, en especial, aquella parte referida a la forma en que debe realizarse la notificación de la cesión de créditos contenidos en una factura, y de cómo -a juicio del autor- la postura adoptada por nuestro máximo tribunal a su respecto, implica una vulneración expresa a la legislación vigente, específicamente, a lo dispuesto en el artículo 7 inciso $2^{\circ}$ de la Ley $\mathrm{N}^{\mathrm{o}} 19.983^{1}$.

En primer término, y antes de comenzar con el análisis de fondo de la sentencia en comento, resulta de vital importancia aclarar los principales argumentos que tuvo la Corte Suprema para rechazar el recurso de casación en el fondo deducido por el ejecutante-Comercial de Valores S.A. Factoring-.

En efecto, la Corte sostiene su postura básicamente en dos grandes argumentos, a saber: en primer lugar, afirma que la notificación de la cesión del crédito de una factura debe realizarse -necesariamente- de forma personal al deudor, resultando insuficiente aquella efectuada mediante carta certificada emitida por un Notario Público. En segundo lugar, la Corte estima que de los antecedentes del proceso, se desprende inequívocamente que el ejecutado pagó al cedente parte del precio de las facturas, situación que se habría verificado con anterioridad a la notificación de la cesión de los créditos, en consecuencia, el pago habría extinguido parcialmente la obligación.

A este respecto, es importante destacar que la decisión de la Corte, en orden a rechazar el recurso de casación en el fondo, resulta acertada, sin perjuicio que parte importante de la argumentación que sostiene tal pronunciamiento adolece de un error insalvable, según se expondrá más adelante.

A propósito del pago, la Corte estimó -correctamente- que la excepción deducida por el ejecutado era oponible al ejecutante, por cuanto los referidos pagos se efectuaron

${ }^{1}$ El referido artículo dispone: Esta cesión deberá ser puesta en conocimiento del obligado al pago de la factura, por un notario público o por el oficial de Registro Civil en las comunas donde no tenga su asiento un notario, sea personalmente, con exhibición de copia del respectivo título, o mediante el envío de carta certificada, por cuenta del cesionario de la factura, adjuntando copias del mismo certificadas por el ministro de fe. En este último caso, la cesión producirá efectos respecto del deudor, a contar del sexto día siguiente a la fecha del envío de la carta certificada dirigida al domicilio del deudor registrado en la factura. 
con anterioridad a la notificación de la cesión de los créditos contenidos en las facturas, lo que en definitiva significa que el ejecutado pagó, a quien en ese entonces era su acreedor.

Ahora bien, es importante aclarar que pese a que la excepción de pago es de carácter real, de todas formas ella no asegura la extinción de la obligación en todas las circunstancias en que el deudor pague directamente al emisor de la factura. Así por ejemplo, si el pago se hubiera realizado al cedente con posterioridad a la notificación de la cesión de los créditos, este habría resultado inoponible al cesionario, aplicándose en contra del que pagó equívocamente, el conocido aforismo jurídico el que paga mal paga dos veces.

Como se puede apreciar, en lo relativo al pago, el razonamiento de la Corte es acertado $^{2}$, situación que difiere sustancialmente de otros pasajes de la sentencia ${ }^{3}$, especialmente los que disponen la obligación de notificar personalmente al deudor la cesión del crédito contenido en una factura.

La Corte en orden a fundar su postura, comienza citando una sentencia emitida por ese mismo tribunal ${ }^{4}$ con fecha 1 de septiembre de 2009 , la que por lo demás, trata de forma detallada la normativa aplicable a la notificación de la cesión de créditos de facturas. A este respecto, y a efectos de evitar cualquier confusión, es importante aclarar desde ya, que la sentencia citada por la Corte no resulta aplicable al caso en particular, por la simple razón que ella se refiere a facturas que fueron extendidas y cedidas con anterioridad a la entrada en vigencia de la Ley $\mathrm{N}^{\circ} 19.983$.

En efecto, y pese a lo cuestionable $e^{5}$ de la tesis que postula la obligatoriedad de notificar personalmente al deudor la cesión de un crédito contenido en una factura ${ }^{6}$, de todas maneras tal discusión resulta aplicable a un contexto diverso al discutido aquí, ya que las facturas objeto de revisión de la sentencia en comento, fueron extendidas y cedidas en el año 2008, es decir, 4 años después de que entrara en vigencia la referida ley.

A mayor abundamiento, y despejando cualquier duda a su respecto, la misma sentencia citada por la Corte, dictaminó: De lo expuesto, es posible inferir que para dilucidar la validez de la notificación de la cesión de créditos contenidos en facturas, deberá entonces distinguirse la fecha en que dichos documentos fueron extendidos y en que se celebró el respectivo contrato de cesión, puesto que a partir del 15 de diciembre de 2004 -fecha en que fue publicada la Ley No 19.983-, no podrá discutirse la eficacia de la notificación practicada por carta certificada, en los términos y con las formalidades que establece del citado artículo 7 de la Ley $N^{\circ} 19.983$.

${ }^{2}$ Los pagos efectuados por el ejecutado y las fechas en que estos se verificaron, es más que suficiente para rechazar de plano el recurso de casación en el fondo, sin resultar necesario entrar a discutir la validez de la notificación de la cesión de créditos efectuada mediante una carta certificada enviada por un Notario Público.

3 Véase considerandos octavo y noveno.

${ }^{4}$ Bancredito Factoring S.A. con Vivanco Keller María, Corte Suprema, 1 de septiembre de 2009, Rol $\mathrm{N}^{\mathrm{o}} 2563-2008$.

${ }^{5}$ En efecto, no existe norma alguna en nuestro ordenamiento jurídico que obligue notificar personalmente la cesión de un crédito. Sin perjuicio de ello, es importante destacar que tanto la doctrina como la jurisprudencia, interpretando el artículo 1903 del Código Civil en relación al artículo 47 del Código de Procedimiento Civil, han llegado - en su mayoría- a tal conclusión.

${ }^{6}$ Postura que inclusive desecha la posibilidad de notificar la cesión del crédito de acuerdo al artículo 44 del Código de Procedimiento Civil. 
Con anterioridad a dicha data, las exigencias que han de requerirse respecto de la notificación de la cesión de créditos contenidos en este tipo de documentos deberán ajustarse estrictamente al tenor de los artículos 1901 y siguientes del Código Civil y/o 162 y 163 del Código de Comercio, según corresponda ${ }^{7}$.

En otras palabras, la propia sentencia que sirvió de consorte a la Corte para fundar su postura en el caso en comento, destacó que la exigencia de notificar personalmente al deudor de la cesión de un crédito contenido en una factura, solo opera respecto de facturas cedidas con anterioridad a la entrada en vigencia de la Ley $\mathrm{N}^{\circ} 19.983$.

De lo anterior, se desprende que la Corte cometió un grave error, ya que fundó su postura en una sentencia cuyos supuestos fácticos difieren completamente a los descritos en el caso objeto de análisis.

Ahora bien, y sin perjuicio de la evidente equivocación de la Corte, aunque se estimara que los argumentos expuestos en los considerandos $8^{\circ}$ y $9^{\circ}$ de la sentencia, más que un error, sostienen una primacía de las normas generales, de todas formas tal postura carece de todo sustento legal, ello según lo dispuesto en el artículo 13 del Código Civil (que consagra el principio de especialidad) con relación al artículo 7 inciso $2^{\circ}$ de la Ley $\mathrm{N}^{\circ} 19.983$.

En efecto, la Ley $\mathrm{N}^{\circ} 19.983$ que regula la transferencia y otorga mérito ejecutivo a la factura, viene a ser ley especial que prevalece sobre las normas generales, no existiendo una doble interpretación a su respecto que permita sostener, por ejemplo, que la notificación efectuada por carta certificada enviada por Notario Público es insuficiente.

En conclusión, y pese a que el pronunciamiento de la Corte pareciera ser un error desafortunado más que una nueva postura jurisprudencial ${ }^{8}$; de todas formas resulta inquietante que nuestro máximo tribunal sea capaz de resolver un asunto con expresa vulneración a la ley.

\footnotetext{
${ }^{7}$ Bancredito Factoring S.A. con Vivanco Keller María, Corte Suprema, 1 de septiembre de 2009, Rol $\mathrm{N}^{\circ}$ 2563-2008. Considerando séptimo. En el mismo sentido: Factoring Creación Quinta Región S.A. con Empresa de Obras Sanitarias de Valparaíso S.A., Corte Suprema, 21 de marzo de 2011, Rol N 4560-2009, $\mathrm{N}^{\circ}$ identificador LegalPublishing: 48203. Considerando decimosexto.

${ }^{8}$ Ello, atendido que funda su postura en una sentencia que se pronunció sobre hechos diversos, en que lo razonado y resuelto se basa en facturas extendidas y cedidas con anterioridad a la entrada en vigencia de la Ley $\mathrm{N}^{\circ} 19.983$, situación que difiere sustancialmente de las facturas que hace referencia la sentencia objeto de análisis.
} 